its similarity to $\beta$-amyloid, the vaccine should have been anticipated to cause adverse effects. "I think that for most of us this was not a big surprise. The concern about a potentially serious adverse effect stemming from inflammation was always in the mix," according to Rudolph Tanzi, professor of neurology at Harvard Medical School, who is also the scientific founder for a competitor company called Neurogenetics.

David Morgan, professor of pharmacology at the University of South Florida and a member of the university's Alzheimer research group agrees. "Introducing the vaccine and making antibodies against the amyloid deposit could cause interactions that activate the immune system even more." He adds that his independent studies with the vaccine offer one possible explanation. "We did find that [it] is associated with an increase in microglial activation-a sign of inflammation-when mice were vaccinated monthly for 3-5 months. Yet 9 months into the treatment we no longer found microglial activation (DNA Cell Bio. 20, 731; 2001). So it is possible that this is a transient period of inflammation in humans receiving the vaccine, which will abate over time," he suggests.

One of the more optimistic explanations is that the adverse events might be due to the QS21 adjuvant used. Data on antibody and T-cell production in patients would give a clearer indication of the problem; however, Elan is under no obligation to release this information generally. In April, Elan's scientific director, Dale Schenk, will give the opening address at the 7th International Springfield Symposium on Advances in Alzheimer Therapy in Geneva, where he may say more about the situation.

Meanwhile, with investors currently suffering from a fear of companies with hidden debts from dubious but not necessarily illegal practices-so-called 'Enronitis'Elan's share price has sunk. The Wall Street
Journal reports that investors have questioned the complex way in which Elan has been investing in joint ventures and then recording license payments of $75 \%$ of the original investment from these ventures as revenue. It is alleged that this allows Elan to avoid the costs when reporting earnings by accounting for the repayment as revenue.

Also, the company issued warnings that revenue growth in 2002 would be slower than expected due to delays in launching new products, such as the migraine treatment Frova, and the chronic pain analgesic Prialt. Elan is also facing several lawsuits for allegedly defrauding investors. A spokesperson for Elan declined to comment on these financial matters, but assured Nature Medicine that, if the vaccine were to be found to be safe, they have enough money in the bank to sustain the continuation of the trial.

Karen Birmingham \& Simon Frantz, London

\section{Scientists resign over stem-cell study...}

Three senior stem cell scientists have quit the Editorial board of an electronic journal to protest the publication of the much heralded "first cloned human embryo" paper released, Somatic Cell Nuclear Transfer in Humans: Pronuclear and Early Embryonic Development.

Cast as pioneering research by the world wide media, the paper reported work by Massachusetts-based Advanced Cell Technology (ACT)-a small firm working towards therapeutic cloning with human and animal cells. They applied nuclear transfer to 17 donor eggs to create the first cloned human 'embryos', 3 of which reached the 6-cell stage of division before dying. However, Davor Solter from the Max Planck Institute for Immunobiology in Germany, John Gearhart of the Johns Hopkins School of Medicine and Robin Lovell-Badge of the National Institute for Medical Research in London felt that they could not endorse the findings published in The Journal of Regenerative Medicine, and have resigned from the journal's board.

Their action compounds the unease of other prominent researchers such as Ian Wilmut, the embryologist at Roslin Institute in Edinburgh, Scotland who helped to create Dolly. "Nuclear transfer to produce human embryos is a very important area of research," says Wilmut. "However, the (ACT) research is very pre- liminary and not ready for publication." But editorial Board member, Tim Brazelton of Stanford Medical School had no problem with the study. "If I had been asked to review the article, I would have accepted it," he says. "It's preliminary but important." As an online journal, it is willing to accept early data from ongoing research so as to allow scientists to quickly integrate new methods into their own experiments, says Brazelton, acknowledging that this is "pushing the boundaries a little bit."

Solter says that the first he heard about the paper was from a reporter who called to ask his opinion. After reading the paper he was unimpressed. The results were overstated and not supported by the published data, he says. "Eggs have a tendency to fragment... You would have to prove...that you have cells there. I cannot see that this paper can claim that any of these embryos developed."

As an avenue of research, stem cells have all the right ingredients to make a winning newspaper story: ethical dilemmas, political angles, medical potential and big money for those who are successful. "All of these things are a bad mix in terms of science and orderly publishing," comments Drummond Rennie, deputy editor with The Journal of the American Medical Association. "They bring out the skirting of the peer-review system. It's a mix that brings out the worst in everybody."

For example, University of Minnesota researcher, Catherine Verfaillie, was waiting to hear whether a journal had accepted her paper describing isolation of omnipotent stem cells from bone marrow of adult mice when she was contacted by the New Scientist. She spoke to the magazine "to make sure what they were going to say is accurate," and several front-page daily newspaper reports followed. And last month, British newspapers announced that ACT had used cells from cloned cow embryos to grow functioning kidney cells even though the work has not yet been submitted to a journal for consideration.

ACT's credibility with the scientific community was partially redeemed by a new Science paper on the use of parthenogenesis to trigger the development of monkey oocytes (Science 295, 819; 2002). Several reached the blastocyte stage before dying, and a single cell from a monkey named Buttercup produced stem cells. Jose Cibelli, ACT's chief scientist, bristles at criticism of the human 'embryo' paper, which he considers to be just as worthy of publication as the monkey paper. "I think they are both important," he says. "When you talk about humans, any data is important because these are humans."

Tinker Ready, Boston 